\title{
Screening and treatments using telemedicine in retinopathy of prematurity
}

This article was published in the following Dove Press journal:

Eye and Brain

17 August 2016

Number of times this article has been viewed

\author{
Aristomenis Thanos' \\ Yoshihiro Yonekawa ${ }^{1,2}$ \\ Bozho Todorich' \\ Darius M Moshfeghi ${ }^{3}$ \\ Michael T Trese' \\ 'Associated Retinal Consultants, \\ William Beaumont Hospital, \\ Royal Oak, MI, ${ }^{2}$ Retina Service, \\ Massachusetts Eye and Ear Infirmary, \\ Harvard Medical School, Boston, MA, \\ ${ }^{3}$ Byers Eye Institute, Horngren Family \\ Vitreoretinal Center, Department of \\ Ophthalmology, Stanford University \\ School of Medicine, Palo Alto, CA, \\ USA
}

\begin{abstract}
Several studies have validated the role of telemedicine as a new powerful screening and diagnostic tool for retinal disorders, such as diabetic retinopathy and retinopathy of prematurity. With regard to retinopathy of prematurity, bedside examination with binocular indirect ophthalmoscopy has been the gold standard technique for screening, yet with several limitations. Herein, we review the current evidence that supports the role of telemedicine for the screening of infants with retinopathy of prematurity.
\end{abstract}

Keywords: retinopathy of prematurity, screening, telemedicine

\section{Introduction}

Advances in diagnostic technologies have revolutionized our understanding and treatment of retinal diseases. The advent of transferrable retinal imaging has enhanced the care of patients with retinopathies by 1) improving diagnostic accuracy, assessment, and documentation and 2) ushering in telemedicine as a new paradigm of delivering care.

With respect to retinopathy of prematurity (ROP), timely screening and early treatment remain the most crucial factors for prevention of lifelong vision-threatening sequelae. Telemedical care of infants with ROP has become a reality. Improvements have been made in image quality and software engineering, and multiple validation studies have demonstrated the efficacy of remote screening. However, bedside examinations remain the mainstay for ROP screening in most practices. This paper will review the rationale for remote photographic screening for ROP.

\section{Current screening for ROP and limitations}

According to the guidelines published jointly by the American Academy of Ophthalmology, American Academy of Pediatrics, and American Association for Pediatric Ophthalmology and Strabismus, infants with birth weight $<1,500 \mathrm{~g}$ or gestational age $\leq 30$ weeks, and infants with birth weight 1,500-2,000 g or gestational age $>30$ weeks with an unstable clinical course should receive dilated ophthalmoscopic examinations for ROP screening. ${ }^{1}$ These exams are most usually performed with binocular indirect ophthalmoscopy (BIO) at the neonatal intensive care unit (NICU) bedside and require the coordination of NICU staff with the screening ophthalmologist. Scleral depression technique is commonly utilized, which can be particularly stressful for premature infants and may cause apnea, bradycardia, and aspiration. ${ }^{2,3}$

$\mathrm{BIO}$ and retinal drawings have been used since the 1950s for the screening and documentation of ROP. Undoubtedly, the development of an international classification
Correspondence: Michael T Trese Associated Retinal Consultants PC, 3535 W. I 3 Mile Road, Suite 344, Royal Oak, MI 48074, USA

Tel + I 2482882280

Email mgjt46@aol.com
Eye and Brain 2016:8 |47-|5|

Dovepress

http://dx.doi.org/10.2147/EB.S94440 (c) (1) (5) 2016 Thanos et al. This work is published and licensed by Dove Medical Press Limited. The full terms of this license are available at https://www.dovepress.com/terms. (c) ${ }_{\mathrm{BY}} \mathrm{NC}$ php and incorporate the Creative Commons Attribution - Non Commercial (unported, v3.0) License (http:///creativecommons.org/licenses/by-nc/3.0/). By accessing the work you hereby accept the Terms. Non-commercial uses of the work are permitted without any further permission from Dove Medical Press Limited, provided the work is properly attributed. For permission for commercial use of this work, please see paragraphs 4.2 and 5 of our Terms (https://www.dovepress.com/terms.php). 
system has allowed standardization of the disease severity, description, and location of retinal abnormalities in ROP. ${ }^{4}$ However, a significant limitation of bedside examination is the subjectivity of the examiner impression of the BIO findings especially in a squirming live exam. Sometimes, a poorly dilated eye of a premature infant, corneal clouding, tunica vasculosa lentis, and vitreous haze render the exam even more challenging. In fact, several studies have shown a wide range of disagreement of ROP diagnosis and severity among health care professionals screening for ROP. ${ }^{5,6}$ In the pivotal CRYO-ROP trial, there was disagreement between two unmasked, certified examiners as to whether threshold disease was present in $12 \%$ of eyes. ${ }^{7}$ Furthermore, the documentation of exam findings is solely based on memory using paper charts with handwritten sketches or, more recently, electronic medical records that utilize drawing tools and templates. The latter makes independent verification of disease status as well as monitoring disease progression particularly challenging.

Conversely, there is an increasing discordance between the number of premature infants requiring ROP screening and the number of ophthalmologists performing it. In 2006, a survey of 224 pediatric ophthalmologists and retinal specialists by the American Academy of Ophthalmology revealed that only $54 \%$ of retinal specialists and pediatric ophthalmologists were willing to manage ROP and $20 \%$ of them were considering stopping due to decreasing reimbursement and high medicolegal liability. ${ }^{8}$

\section{Telemedicine for ROP screening}

Telemedicine refers to the use of telecommunication and information technologies in order to provide clinical health care at a distance. 9 With regard to "store-and-forward" telemedicine, it involves capturing of patient data usually by nonphysician providers for subsequent interpretation by a remote expert. Numerous studies have shown that photographic screening using contact wide-field cameras can detect treatment and/or referral-warranted ROP at a rate that is safe and comparable to live screening with BIO. ${ }^{1}$ These results were fairly consistent even among different camera operators, who included trained ophthalmologists, ${ }^{10-12}$ ophthalmic photographers, ${ }^{13-15}$ or trained neonatal personnel. ${ }^{14,16,17}$ Most of the studies have compared the gold standard for ROP screening, that is, BIO bedside exam, against wide-angle contact imaging systems (eg, RetCam; Clarity Medical Systems, Pleasanton, CA, USA). The e-ROP study was a multicenter study to test the ability of nonphysicians to recognize referral warranted-ROP or alternatively ROP at high risk of causing vision loss. In addition, $43 \%$ of severe
ROP cases were identified by telemedicine before they were detected by an ophthalmologist which was on average 2 weeks earlier. ${ }^{18,19}$ This is likely due to being able to objectively track the progression of the fundus appearance - one of the largest advantages of photographic screening.

With $>15$ years of studies validating the accuracy and sensitivity of telemedicine in ROP screening, several live telemedicine programs have already demonstrated promising results. ${ }^{20}$ The Stanford University Network for Diagnosis of Retinopathy of Prematurity telemedicine program has been screening five NICUs in the San Francisco Bay area since December 2005. The recently published 6-year results were highly favorable with respect to diagnostic accuracy of ROP. ${ }^{21}$ Remote interpretation of images had a sensitivity of $100 \%$, specificity of $99.8 \%$, positive predictive value of $95.5 \%$, and negative predictive value of $100 \%$ for the detection of treatment-warranted ROP. No adverse anatomical outcomes were observed for any infant. Similar results were demonstrated from telemedicine programs in Germany ${ }^{22}$ and India. ${ }^{23}$ In the authors' group, remote ROP screening led to a reduction of live exams by $84 \%$ without any infant missing a treatment interval (Figure 1). ${ }^{24}$

It has been shown that the clinical determination of zone 1 ROP disease and the presence of plus disease is imperfect, ${ }^{6,25}$ which has important implications since the majority of ROP treatment decisions are based on the presence of plus or zone 1 disease. ${ }^{26}$ Photographic screening may be particularly helpful in the diagnosis of plus disease and type 1 ROP in general as several sophisticated software programs can now objectively quantify the amount of retinal vessel tortuosity ${ }^{27-29}$ or assist in the determination of zone 1 (Figure 2A). In a study performed by Abbey et al, ${ }^{30}$ utilizing the ROP Tool for detecting plus disease, 93\% of images were able to be processed by the tool. It is anticipated that new cameras with better image acquisition will aid in increasing this percentage even further.

\section{Other advantages of telemedicine in ROP screening}

A clear advantage of utilizing telemedicine in the screening of ROP lies in the fact that it allows improved access to health care by overcoming geographical challenges. This is especially true given that ROP screening is traditionally performed by highly specialized professionals who may not be accessible for rural NICUs. ${ }^{31}$ Telemedicine allows immediate communication between local health care providers and expert consultants in a cost-effective manner. ${ }^{32,33}$ Scheduling conflicts are avoided and labor costs are decreased. Telemedicine 


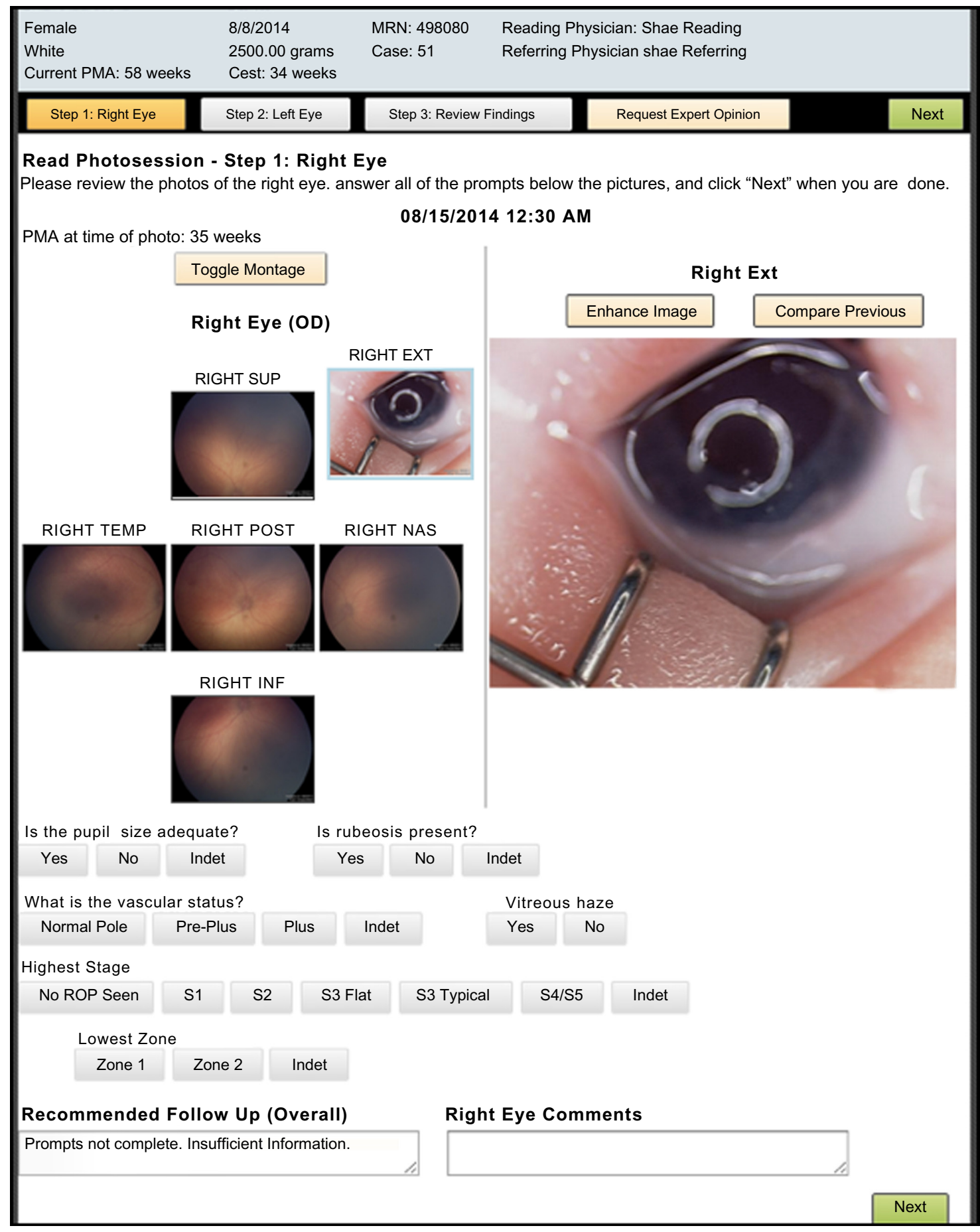

Figure I Computer screenshot of the interface of a telemedicine software.

Notes: A standard set of six photos is captured (external photo, posterior pole centered around the nerve, temporal, nasal, inferior, and superior). The software is capable of generating a montage of the acquired images.

Abbreviations: PMA, post-menstrual age; Cest, gestational age; SUP, superior; EXT, external; TEMP, temporal; POST, posterior pole; NAS, nasal; INF, inferior; Indet, indeterminate; SI, Stage I; S2, Stage 2; S3 Flat, Stage 3 with flat neovascularization; S4/S5, Stage 4/Stage5.

examinations also require significantly less physician time than standard BIO bedside examinations. ${ }^{34}$

Furthermore, the acquisition of fundus photographs aids in the education of parents. Clinical imaging illuminates the disease patterns seen in ROP for patients families, an entity otherwise abstract and difficult to comprehend. Clinical improvement would also be easier to document and convey to the patient, families, and other members of the patient care team. Fundus photographs can also serve as educational tools for less experienced ROP screeners or those in training. 

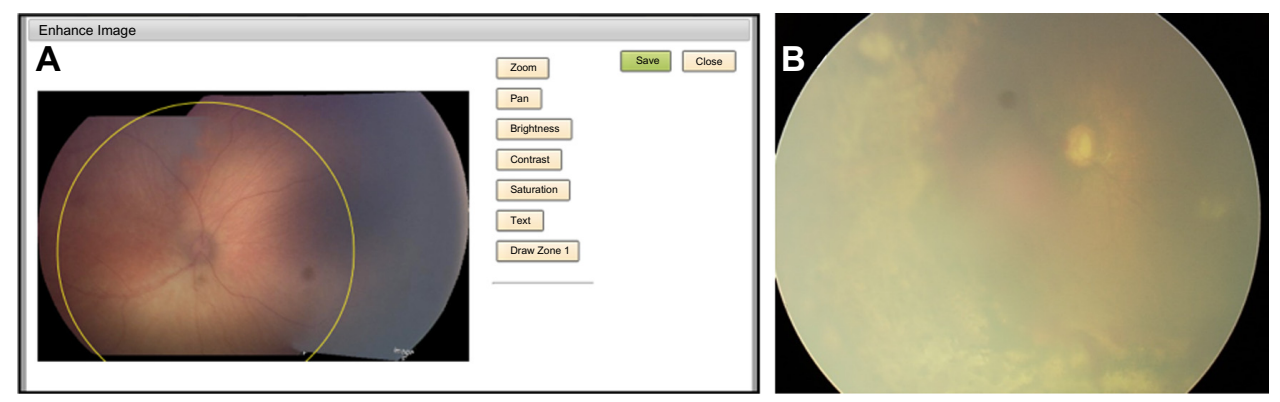

Figure 2 Computerized Zone I determination.

Notes: (A) Computerized software determination of Zone I in retinopathy of prematurity (ROP) (yellow circle). Notice the image processing capabilities (change brightness, contrast, and color saturation), which can aid in the modification of the original photo to allow a more accurate review. (B) Fundus image of the left eye of an infant with a heavily pigmented fundus obtained with a wide-field contact fundus camera (RetCam; Clarity Medical Systems, Pleasanton, CA, USA) and type I ROP requiring laser treatment. Media opacity is due to vitreous hemorrhage, which renders the retinal vessels difficult to discern.

Sick infants are often transferred to tertiary care institutes where expert ROP treaters are accessible, but rural hospitals are often caring for less acutely ill infants, and ROP screeners in such clinical facilities may not be as familiar with the nuances of advanced ROP. Ongoing continuing education can therefore be incorporated into telemedicine screening programs.

Finally, telemedicine allows unequivocal documentation. The medicolegal climate surrounding ROP has always been complex and a deterrent for the recruitment of more screeners and treaters. While malpractice claims are, in fact, very rare, each lawsuit can be costly. ${ }^{35}$ Physicians should be aware of risk management strategies, and photodocumentation is one method of demonstrating sound clinical practice and judgment, should legal action occur.

\section{Limitations and other considerations}

Image quality is an important factor for effective and reliable ROP screening. This is particularly an issue in darkly pigmented fundi or infants with small palpebral fissures, which prevent adequate contact of the camera and the corneal surface (Figure 2B). Vitreous or corneal haze due to extreme prematurity, vitreous hemorrhage, or motion artifacts are also additional factors that can affect image quality rendering their interpretation challenging. Uninterpretable images range from $8 \%$ to $21 \%$ in published studies. ${ }^{10,15}$

In addition, some may argue that the high cost of a widefield imaging camera is prohibitive for participation in telemedicine programs. Even the smaller, more affordable retinal cameras cost $\sim \$ 90,000-\$ 140,000$, a cost difficult to absorb for smaller institutions. It is hoped that the advent of newer, costeffective imaging technology would allow for more centers to participate in the screening of ROP via telemedicine. Of equal importance is medicolegal liability for telemedicine in
ROP. Considering its relatively recent introduction in clinical practice, the legislation concerning telemedicine can be poorly defined and laws governing medical liability may differ from state to state regarding telemedicine.

\section{Conclusion}

In summary, telemedicine provides better documentation of disease severity and progression and appears to have several advantages over traditional bedside examination, which has been the gold standard for ROP screening. The future of ROP screening is to provide objective data by reducing subjectivity and potentially human error. The beauty of telemedicine lies in the fact that it provides the platform for reduction of subjectivity in ROP by providing objective data overseen by physicians thus providing high quality care.

\section{Disclosure}

AT, BT, and YY have no financial or proprietary interest in the materials presented herein. MTT is founder and equity partner of Focus ROP, partner in Pediatric Wide Angle Camera LLC, and licensed ROP Tool. DMM is director of telemedicine at Byers Eye Institute and has equity in Visunex Medical Systems. The authors report no other conflicts of interest in this work.

\section{References}

1. Fierson WM; American Academy of Pediatrics Section on Ophthalmology, American Academy of Ophthalmology, American Association for Pediatric Ophthalmology and Strabismus, American Association of Certified Orthoptists. Screening examination of premature infants for retinopathy of prematurity. Pediatrics. 2013;131(1):189-195.

2. Rush R, Rush S, Nicolau J, Chapman K, Naqvi M. Systemic manifestations in response to mydriasis and physical examination during screening for retinopathy of prematurity. Retina. 2004;24(2):242.

3. Laws DE, Morton C, Weindling M, Clark D. Systemic effects of screening for retinopathy of prematurity. Br J Ophthalmol. 1996;80(5): $425-428$ 
4. An international classification of retinopathy of prematurity. The Committee for the Classification of Retinopathy of Prematurity. Arch Ophthalmol. 1984;102(8):1130-1134.

5. Paul Chan RV, Williams SL, Yonekawa Y, Weissgold DJ, Lee TC, Chiang MF. Accuracy of retinopathy of prematurity diagnosis by retinal fellows. Retina (Philadelphia, Pa). 2010;30(6):958-965.

6. Chiang MF, Jiang L, Gelman R, Du YE, Flynn JT. Interexpert agreement of plus disease diagnosis in retinopathy of prematurity. Arch Ophthalmol. 2007;125(7):875-880.

7. Multicenter trial of cryotherapy for retinopathy of prematurity. Preliminary results. Cryotherapy for Retinopathy of Prematurity Cooperative Group. Arch Ophthalmol. 1988;106(4):471-479.

8. Celia, F. An ophthalmology crisis: retinopathy of prematurity. Retinal Physician; 2006. Available from: http:/www.retinalphysician.com/ printarticle.aspx?articleID=100242. Accessed October 27, 2015.

9. Field MJ, Grigsby J. Telemedicine and remote patient monitoring. JAMA 2002;288(4):423-425.

10. Photographic Screening for Retinopathy of Prematurity (Photo-ROP) Cooperative Group, Balasubramanian M, Capone A, Hartnett ME, Pignatto S, Trese MT. The Photographic Screening for Retinopathy of Prematurity Study (Photo-ROP): study design and baseline characteristics of enrolled patients. Retina. 2006;26(7 Suppl):S4-S10.

11. Schwartz SD, Harrison SA, Ferrone PJ, Trese MT. Telemedical evaluation and management of retinopathy of prematurity using a fiberoptic digital fundus camera. Ophthalmology. 2000;107(1):25-28.

12. Ells AL, Holmes JM, Astle WF, et al. Telemedicine approach to screening for severe retinopathy of prematurity: a pilot study. Ophthalmology. 2003;110(11):2113-2117.

13. Chiang MF, Keenan JD, Starren J, et al. Accuracy and reliability of remote retinopathy of prematurity diagnosis. Arch Ophthalmol. 2006;124(3):322-327.

14. Roth DB, Morales D, Feuer WJ, Hess D, Johnson RA, Flynn JT. Screening for retinopathy of prematurity employing the retcam 120: sensitivity and specificity. Arch Ophthalmol. 2001;119(2):268-272.

15. Wu C, Petersen RA, VanderVeen DK. RetCam imaging for retinopathy of prematurity screening. J AAPOS. 2006;10(2):107-111.

16. Chiang MF, Wang L, Busuioc M, et al. Telemedical retinopathy of prematurity diagnosis: accuracy, reliability, and image quality. Arch Ophthalmol. 2007;125(11):1531-1538.

17. Lajoie A, Koreen S, Wang L, et al. Retinopathy of prematurity management using single-image vs multiple-image telemedicine examinations. Am J Ophthalmol. 2008;146(2):298-309.

18. Graham E Quinn, e-ROP Cooperative Group. Telemedicine approaches to evaluating acute-phase retinopathy of prematurity: study design. Ophthalmic Epidemiol. 2014;21(4):256-267.

19. Quinn GE, Ying G-S, Daniel E, et al. Validity of a telemedicine system for the evaluation of acute-phase retinopathy of prematurity. JAMA Ophthalmol. 2014;132(10):1178-1184.

20. Chiang MF, Melia M, Buffenn AN, et al. Detection of clinically significant retinopathy of prematurity using wide-angle digital retinal photography: a report by the American Academy of Ophthalmology. Ophthalmology. 2012;119(6):1272-1280.
21. Wang SK, Callaway NF, Wallenstein MB, Henderson MT, Leng T, Moshfeghi DM. SUNDROP: six years of screening for retinopathy of prematurity with telemedicine. Can J Ophthalmol. 2015;50(2):101-106.

22. Lorenz B, Spasovska K, Elflein H, Schneider N. Wide-field digital imaging based telemedicine for screening for acute retinopathy of prematurity (ROP). Six-year results of a multicentre field study. Graefes Arch Clin Exp Ophthalmol. 2009;247(9):1251-1262.

23. Vinekar A, Jayadev C, Mangalesh S, Shetty B, Vidyasagar D. Role of tele-medicine in retinopathy of prematurity screening in rural outreach centers in India - A report of 20,214 imaging sessions in the KIDROP program. Semin Fetal Neonatal Med. 2015;20(5):335-345.

24. Trese MT, Drenser K, Capone A. Telemedicine for ROP screening. Invest Ophthalmol Vis Sci. 2014;55(13):5905-5905.

25. Chiang MF, Thyparampil PJ, Rabinowitz D. Interexpert agreement in the identification of macular location in infants at risk for retinopathy of prematurity. Arch Ophthalmol. 2010;128(9):1153-1159.

26. Solarte CE, Awad AH, Wilson CM, Ells A. Plus disease: why is it important in retinopathy of prematurity? Middle East Afr J Ophthalmol. 2010;17(2):148-155.

27. Gelman R, Martinez-Perez ME, VanderVeen DK, Moskowitz A, Fulton AB. Diagnosis of plus disease in retinopathy of prematurity using Retinal Image multiScale Analysis. Invest Ophthalmol Vis Sci. 2005;46(12):4734-4738.

28. Cheung CSY, Butty Z, Tehrani NN, Lam WC. Computer-assisted image analysis of temporal retinal vessel width and tortuosity in retinopathy of prematurity for the assessment of disease severity and treatment outcome. J AAPOS. 2011;15(4):374-380.

29. Koreen S, Gelman R, Martinez-Perez ME, et al. Evaluation of a computer-based system for plus disease diagnosis in retinopathy of prematurity. Ophthalmology. 2007;114(12):e59-e67.

30. Abbey AM, Besirli CG, Musch DC, et al. Evaluation of Screening for Retinopathy of Prematurity by ROPtool or a Lay Reader. Ophthalmology. 2016;123:385-390.

31. Weaver DT, Murdock TJ. Telemedicine detection of type 1 ROP in a distant neonatal intensive care unit. J AAPOS. 2012;16:229-233.

32. Jackson KM, Scott KE, Graff Zivin J, et al. Cost-utility analysis of telemedicine and ophthalmoscopy for retinopathy of prematurity management. Arch Ophthalmol. 2008;126(4):493-499.

33. Castillo-Riquelme MC, Lord J, Moseley MJ, Fielder AR, Haines L. Cost-effectiveness of digital photographic screening for retinopathy of prematurity in the United Kingdom. Int J Technol Assess Health Care. 2004;20(2):201-213.

34. Richter GM, Sun G, Lee TC, et al. Speed of telemedicine vs ophthalmoscopy for retinopathy of prematurity diagnosis. Am J Ophthalmol. 2009;148(1):136-142.e2.

35. Day S, Menke AM, Abbott RL. Retinopathy of prematurity malpractice claims: the ophthalmic mutual insurance company experience. Arch Ophthalmol. 2009;127(6):794-798.
Eye and Brain

\section{Publish your work in this journal}

Eye and Brain is an international, peer-reviewed, open access journal focusing on clinical and experimental research in the field of neuroophthalmology. All aspects of patient care are addressed within the journal as well as basic research. Papers covering original research, basic science, clinical and epidemiological studies, reviews and evaluations,

\section{Dovepress}

guidelines, expert opinion and commentary, case reports and extended reports are welcome. The manuscript management system is completely online and includes a very quick and fair peer-review system, which is all easy to use. Visit http://www.dovepress.com/testimonials.php to read real quotes from published authors. 